Revista Oficial del Poder Judicial

ÓRGANO DE INVESTIGACIÓN DE LA CORTE SUPREMA DE JUSTICIA DE LA REPÚBLICA DEL PERÚ

Vol. 10, n. ${ }^{\circ}$ 12, julio-diciembre, 2019, 203-206

ISSN versión impresa: 1997-6682

ISSN versión electrónica: 2663-9130

DOI: https://doi.org/10.35292/ropj.u10i12.30

\title{
V Encuentro Internacional de los Poderes Judiciales de Perú e Iberoamérica y VII Encuentro Nacional de los Presidentes de las Cortes Superiores de Justicia de Personas en Condición de Vulnerabilidad y Justicia en tu Comunidad
}

0

\section{COMPROMISO DE ICA}

En la ciudad de Ica, los días 26, 27 y 28 de noviembre de 2018 se llevó a cabo el V Encuentro Internacional de los Poderes Judiciales de Perú e Iberoamérica y el VII Encuentro Nacional de los Presidentes de las Cortes Superiores de Justicia y Responsables del Programa Nacional de Acceso a la Justicia de Personas en Condición de Vulnerabilidad y Justicia en tu Comunidad.

REAFIRMANDO el compromiso institucional del Poder Judicial para la defensa y promoción de los derechos fundamentales de las personas en condición de vulnerabilidad, la Comisión Permanente de Acceso a la Justicia de Personas en Condición de Vulnerabilidad y 
Justicia en tu Comunidad, los presidentes de las 34 Cortes Superiores de Justicia y sus responsables distritales declaran lo siguiente:

CONMEMORAMOS el décimo aniversario de la aprobación de las 100 Reglas de Brasilia en la XIV Edición de la Cumbre Judicial Iberoamericana, a las cuales el Poder Judicial se adhirió para efectivizar el acceso a la justicia de las personas en condición de vulnerabilidad en todo el país.

RESALTAMOS que el Poder Judicial se encuentra ejecutando exitosamente las actividades y cumpliendo con los objetivos de los ejes de trabajo del Plan Nacional de Acceso a la Justicia de Personas en Condición de Vulnerabilidad 2016-2021, al bicentenario de nuestra nación, para la eficacia de las Reglas de Brasilia.

GARANTIZAREMOS el efectivo acceso a la justicia de todas las personas en condición de vulnerabilidad por razón de su edad, género, orientación sexual e identidad de género, estado físico o mental, o por circunstancias sociales, económicas, étnicas y/o culturales, o relacionadas con sus creencias y/o prácticas religiosas, $\mathrm{o}$ la ausencia de estas encuentran especiales dificultades para ejercitar con plenitud ante el sistema de justicia los derechos reconocidos por el ordenamiento jurídico.

ASEGURAREMOS la protección de las niñas, niños y adolescentes y los cuidados que sean necesarios para su bienestar, teniendo en cuenta los derechos y deberes de sus padres, tutores u otras personas responsables de ellos ante la ley y, con ese fin, tomando todas las medidas respectivas y en consideración primordial de su interés superior.

FORTALECEREMOS las actividades y servicios judiciales a favor de los adolescentes en conflicto con la ley penal, promoviendo la aplicación de la mediación penal juvenil bajo el enfoque de la justicia restaurativa. 
NOS COMPROMETEMOS a luchar contra todas las formas de discriminación y violencia hacia las niñas, adolescentes y mujeres, como grupo en situación de vulnerabilidad por su condición de género.

APLICAREMOS el servicio de justicia itinerante en todas las regiones del país para garantizar el efectivo acceso a la justicia de las personas en condición de vulnerabilidad que no puedan trasladarse a las instalaciones judiciales por razones económicas, sociales o culturales.

RECONOCEMOS la plena capacidad de ejercicio de las personas adultas mayores y de las personas con discapacidad, en igualdad de condiciones con las demás y en todos los aspectos de la vida, independientemente de si usan o requieren de ajustes razonables o apoyos para la manifestación de su voluntad.

PROPICIAREMOS que la condición migratoria de una persona no puede ser obstáculo en el acceso a la justicia para la defensa de sus derechos fundamentales.

VELAREMOS por la dignidad de la persona privada de libertad, ya sea por motivo de la investigación de un delito, por el cumplimiento de una condena penal, por enfermedad mental o por cualquier otro motivo, y por sus garantías fundamentales, conforme a los instrumentos internacionales sobre derechos humanos.

NOS ASEGURAREMOS de que el trato que reciban las personas pertenecientes a pueblos indígenas, por parte del sistema de justicia ordinario, sea respetuoso con su dignidad, idioma y tradiciones culturales.

SUSCRIBIREMOS convenios y encuentros de cooperación interinstitucional con otros países de la región iberoamericana, como el suscrito con el Superior Tribunal de Corrientes de Argentina y el Encuentro Binacional Perú-Ecuador contra la Trata de Personas, 
para la promoción de los derechos fundamentales de las personas en condición de vulnerabilidad y compartir buenas prácticas judiciales, para la ejecución de las Reglas de Brasilia.

SALUDAMOS el esfuerzo, la hospitalidad y el compromiso institucional de la Corte Superior de Justicia de Ica, representada por el señor presidente Julio César Leyva Pérez, y los magistrados y servidores que integran su equipo de trabajo, como anfitrión de los encuentros internacional y nacional antes referidos.

AGRADECEMOS la participación y aportes de suma importancia de las experiencias y buenas prácticas judiciales de los representantes de los países hermanos de Argentina, Brasil y Ecuador, para la implementación de las Reglas de Brasilia.

ACORDAMOS que la próxima sede donde se llevará a cabo el VI Encuentro Internacional de los Poderes Judiciales de Perú e Iberoamérica y el VIII Encuentro Nacional de Presidentes de las Cortes Superiores de Justicia y Responsables del Programa Nacional de Acceso a la Justicia y Responsables del Programa Nacional de Acceso a la Justicia de Personas en Condición de Vulnerabilidad y Justicia en tu Comunidad será Ucayali.

RATIFICAMOS el compromiso del Poder Judicial, a través de las acciones que realiza la Comisión Permanente de Acceso a la Justicia de Personas en Condición de Vulnerabilidad y Justicia en tu Comunidad, aplicando los enfoques de derechos humanos, género, discapacidad e interculturalidad, en concordancia con los objetivos de la Agenda 2030 para el Desarrollo Sostenible de las Naciones Unidas.

Ica, 28 de noviembre de 2018 